\title{
Basal Metabolic Rate of the Black-Faced Sheathbill (Chionis minor): Intraspecific Variation in a Phylogenetically Distinct Island Endemic
}

\author{
Gregory T. W. McClelland ${ }^{1, *}$ \\ Andrew E. McKechnie ${ }^{2}$ \\ Steven L. Chown ${ }^{3}$ \\ ${ }^{1}$ Centre for Invasion Biology, Department of Botany and \\ Zoology, Stellenbosch University, Private Bag X1, Matieland \\ 7600, South Africa; ${ }^{2}$ DST-NRF Centre of Excellence at the \\ Percy FitzPatrick Institute, Department of Zoology and \\ Entomology, University of Pretoria, Pretoria, South Africa; \\ ${ }^{3}$ School of Biological Sciences, Monash University, Victoria \\ 3800, Australia
}

Accepted 12/15/2015; Electronically Published 1/29/2016

Online enhancements: Nexus files.

\begin{abstract}
Metabolic rate is a fundamental characteristic of all organisms. It covaries most significantly with activity, body mass, seasonality, and temperature. Nonetheless, substantial additional variation in metabolic rate, especially either resting rate or basal rate, is associated with a range of factors including phylogenetic position, ecological distinctiveness, range position, and diet. Understanding this variation is a key goal of physiological ecology. The black-faced sheathbill is a phylogenetically distinct, highlatitude, island-endemic bird occurring exclusively on several archipelagos in the southern Indian Ocean. Here we examined the idea that the unique phylogenetic position and ecology of the black-faced sheathbill may lead to a basal metabolic rate (BMR) different from that predicted by its body mass. When compared with BMR data available for all birds and a subset of island species, it was clear that the BMR of the black-faced sheathbill on subantarctic Marion Island, estimated at $15^{\circ} \mathrm{C}$ using indirect calorimetry $(2.370 \pm 0.464 \mathrm{~W}$, mean $\pm \mathrm{SD} ; n=22)$, for a group of birds with a mean mass of $459 \pm 64 \mathrm{~g}$, is no different from that expected based on body mass. However, variation in BMR, associated with habitat use and diet, even when correcting for variation in mass, was found. Sheathbills foraging year-round in comparatively resource-rich king penguin colonies have a higher BMR $(2.758 \pm 0.291 \mathrm{~W}, n=12)$ than sheathbills that split their foraging between rockhopper penguin colonies and the intertidal zone $(2.047 \pm 0.303 \mathrm{~W}, n=$
\end{abstract}

${ }^{*}$ Corresponding author; e-mail: mcclellandgreg@gmail.com.

Physiological and Biochemical Zoology 89(2):141-150. 2016. (C) 2016 by The University of Chicago. All rights reserved. 1522-2152/2016/8902-4096\$15.00. DOI: $10.1086 / 685411$
$10)$, which are poorer in resources. Because these populations coexist at relatively small spatial extents (the entire island is $290 \mathrm{~km}^{2}$ ), other factors seem unlikely as causes of this variation.

Keywords: Chionidae, endemism, energetics, insular, metabolic diversity.

\section{Introduction}

Basal metabolic rate (BMR) is the rate of metabolism of a resting, normothermic, postabsorptive, nonreproductive endotherm, measured during the inactive circadian phase at a thermoneutral temperature (McNab 1997). It accounts for upward of 40\%-50\% of the total daily energy budget in free-living individuals (Bryant 1997) and is a significant correlate of behavior, distribution, and life history (Brown et al. 2004; White et al. 2007a). In turn, BMR is influenced most significantly by body mass and to a lesser extent by temperature (White et al. 2007b; White and Kearney 2012) and also shows substantial residual variation. This residual variation has phylogenetic (Hayssen and Lacy 1985; Kozlowski and Konarzewski 2004), ecological (Lovegrove 2000; McNab 2003a, 2009), and geographic (McNab 2002; Wikelski et al. 2003) components.

Species or groups that are phylogenetically or ecologically distinct often have BMRs different from those expected from allometry or temperature alone (McNab 1995, 1996; Bozinovic et al. 2004). In birds, many taxa have been studied, often comprehensively (McKechnie and Wolf 2004; Jetz et al. 2008; McNab 2009). However, several significant clades have not been investigated. Many of these are unusually placed on the bird phylogeny, are restricted to islands, or have unusual life histories. In consequence, they might be expected to add substantial variation to the distribution of bird BMR (McNab 1992; White et al. 2012), although the likely scope of this additional variation remains poorly known.

A hitherto little-studied suite of factors that may further contribute to variation in avian BMR is associated with conspecific populations that have distinct habitats or diets or are separated spatially (McNab 2003a, 2009; Piersma et al. 2004; McKechnie and Swanson 2010). Such among-population and amongindividual trait variation is increasingly being recognized as an important contributor to the structuring of assemblages (Bolnick et al. 2011; Violle et al. 2012). Investigating the magnitude and source(s) of intraspecific metabolic variation is therefore important for understanding BMR evolution (Konarzewski and Książek 2012) and the ways in which assemblages are structured. 
Here, we test the ideas that phylogeny and endemism should contribute to variation in BMR in addition to that expected from allometry and that colocated populations that experience quantitative and/or qualitative differences in resource availability should differ in energetic traits such as BMR. We do so using the black-faced sheathbill (Chionis minor Hartlaub) from subantarctic Marion Island. The family Chionididae is phylogenetically distinct, serving as an intermediate between the more typical wader-like Charadriiformes and the morphologically specialized marine clade comprising alcids, gulls, and allies (Livezey 2010). Comprising four morphologically (Bried and Jouventin 1997) and genetically (Viot et al. 1993) distinct subspecies, each restricted to their respective archipelagos in the southern Indian Ocean, black-faced sheathbills are members of the small ecological group of temperate island-endemic birds. Marion Island sheathbills are also well suited for examining intraspecific metabolic variation associated with factors related to foraging habitat and diet. Though all sheathbills can be described as opportunistic omnivores, the Marion Island population can be divided into two distinct and sympatric groups. One group (hereafter referred to as KP sheathbills) forages year-round in continuously occupied king penguin (Aptenodytes patagonicus Miller) colonies, where the sheathbills consume mostly the stomach contents of penguins obtained through kleptoparasitism, penguin carcasses, and excreta (Burger 1984). The second group (hereafter referred to as RH sheathbills) occupies eastern rockhopper penguin (Eudyptes chrysocome filholi Hutton) colonies during the penguins' breeding season, and their diet is similar to that of KP sheathbills during this period (Burger 1981b, 1984). However, when rockhopper penguins leave the island after their 5-mo breeding season (mid-November to mid-March; Crawford et al. 2003), RH sheathbills are forced to forage elsewhere for the remainder of the year. Many of these birds would traditionally forage for terrestrial invertebrates, but competition with invasive mice has lowered prey abundance to the point of dietary insignificance (Huyser et al. 2000; McClelland 2013). The majority of RH sheathbills currently forage in the intertidal zone, where they feed mainly on polychaete worms. The two sheathbill groups differ in body size, clutch size, chick production, and behavior (McClelland 2013). While the rate of philopatry is unknown, no breeding birds changed habitat groups over a 3-yr period $(n=225)$. Moreover, many territory-holding adults rarely traveled more than $200 \mathrm{~m}$ afield (G. T. W. McClelland and S. L. Chown, unpublished data), and some birds conceivably live beyond 2 decades within a few hundred meters of one another yet experience a disparate life history. Thus, the black-faced sheathbill on Marion Island offers a potentially tractable model to investigate the causes and consequences of intraspecific variation in avian metabolic rates.

\section{Material and Methods}

Study Site and Animal Capture

This study took place on subantarctic Marion Island ( $46^{\circ} 54^{\prime} \mathrm{S}$, $\left.37^{\circ} 45^{\prime} \mathrm{E}\right)$. The island is situated to the north of the Antarctic Polar Front and together with smaller Prince Edward Island makes up the Prince Edward Island group. Though the two islands lay $19 \mathrm{~km}$ apart, sheathbills appear to be reluctant to leave shore, and no exchange of individuals between the two islands has been recorded. Marion Island has an area of $290 \mathrm{~km}^{2}$ and a total coastline of $72 \mathrm{~km}$. The island's climate is best described as oceanic, characterized by strong winds, high humidity and rainfall, and low daily temperature variation (mean monthly temperatures range between $3^{\circ}$ and $8.5^{\circ} \mathrm{C}$ ). A comprehensive overview of the climate, geology, and biology of the islands is provided by Chown and Froneman (2008).

Measurements took place during April and May 2011, several weeks after the sheathbill breeding season and the start of winter foraging behavior. Sheathbills were captured by hand within a $5-\mathrm{km}$ stretch of coastline east of the research station (fig. 1). All individuals were selected from a 3-yr study population, and only adults that had bred or attempted to breed during the preceding breeding season were measured. Birds were weighed to the nearest $5 \mathrm{~g}$ using a 1,000-g Pesola spring scale ( \pm 3 g; Baar, Zug, Switzerland). Measurements occurred near the end of the wing molt period, and molt status was determined from plumage examination (molt scores of $\geq 47$; de Beer et al. 2001). The study, which includes individually marked birds (McClelland 2013), enabled us to distinguish birds from the RH and KP groups, and 12 and 10 birds were sampled from each group, respectively. Of these, 9 and 4 were female birds, respectively, sexed on the basis of mate comparison, where the smaller member of the breeding pair is considered female (Burger 1980).

Birds were housed in individual shade cloth cages $\left(0.15 \mathrm{~m}^{3}\right)$ in a room kept at outdoor ambient air temperature $\left(5.0^{\circ} \pm\right.$ $1.8^{\circ} \mathrm{C} \mathrm{SD}$, measured by a standard mercury thermometer, read every hour). All birds were released within $26 \mathrm{~h}$ of capture. The work was done under ethics permit 11NP_CHO01 from

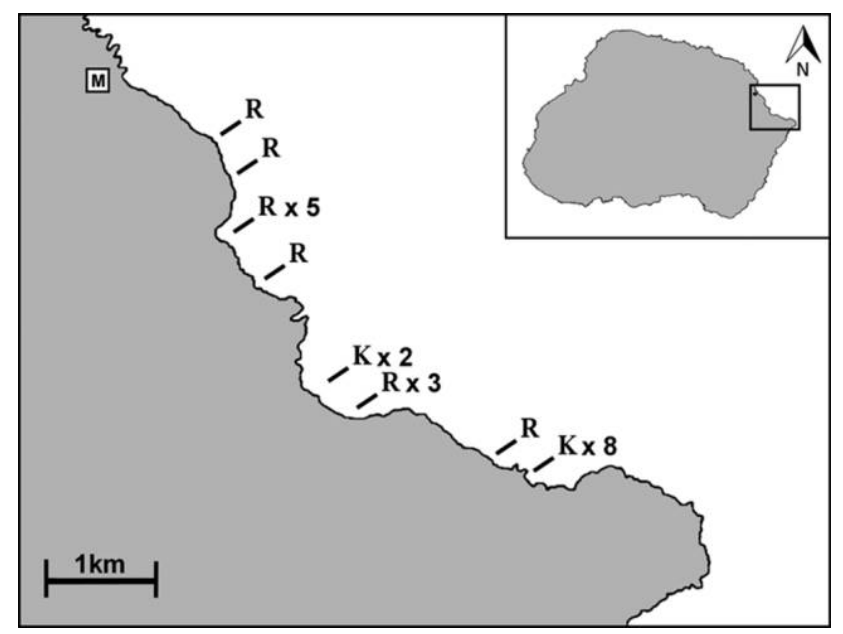

Figure 1. Sheathbill study area depicting the territory locations of measured king penguin $(K)$ and rockhopper $(\mathrm{R})$ sheathbills ( $\mathrm{x}$ indicates the number of birds from each location if greater than 1) and the island research station $(\mathrm{M})$. 


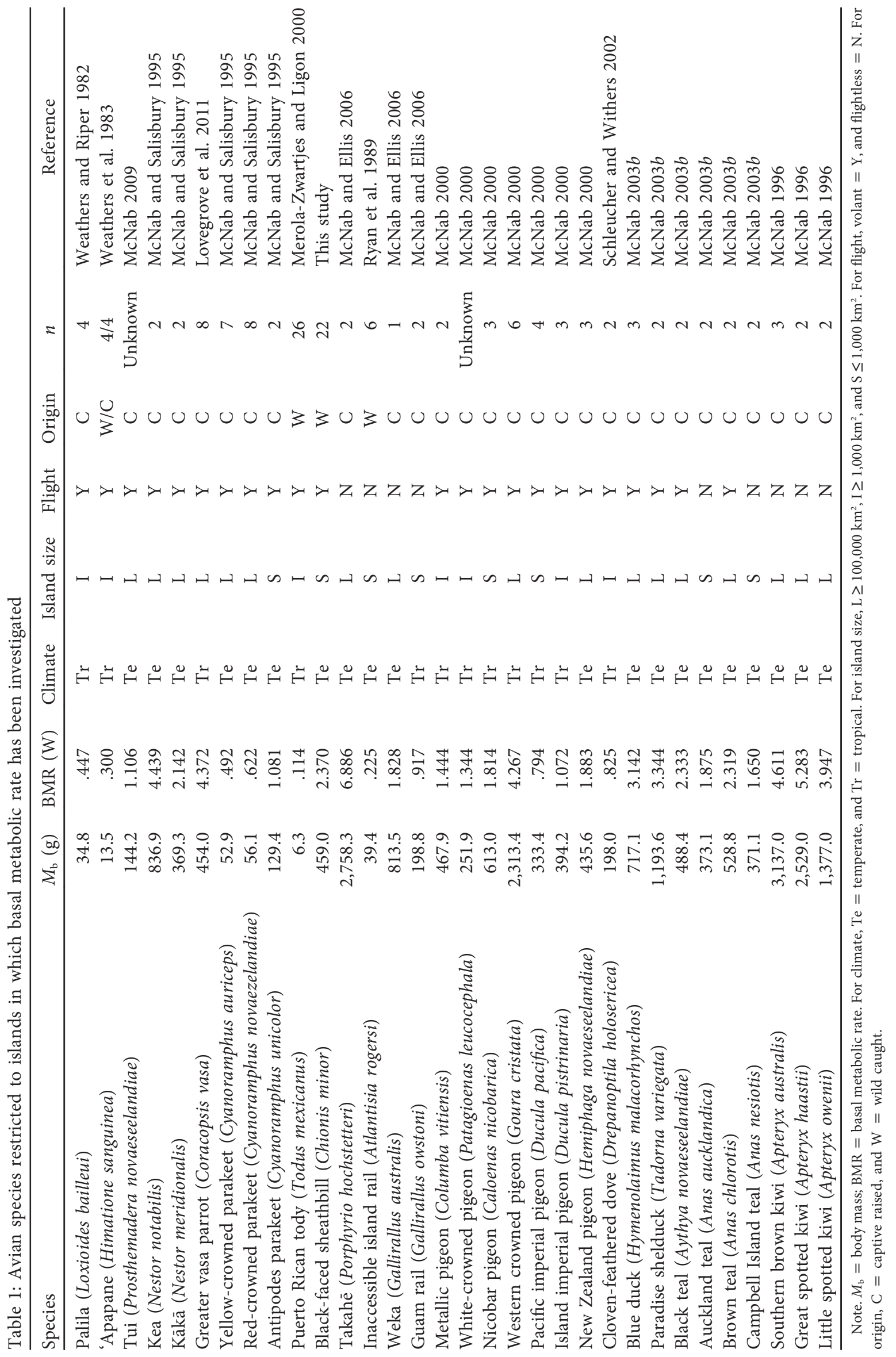

This content downloaded from 137.215.006.052 on May 24, 2016 00:25:26 AM 
Stellenbosch University and with the approval of the Prince Edward Islands Management Committee.

\section{Gas Exchange Measurements}

Metabolic rate was estimated by indirect calorimetry from measurements of oxygen consumption $\left(\dot{\mathrm{V}}_{2}\right)$ obtained using an open flow-through respirometry system as set out in Lighton (2008) and set up at the island's research station. Only one bird was measured at a time. Birds were placed in a darkened 30-L (width and length $=300 \mathrm{~mm}$, height $=333 \mathrm{~mm}$ ) plastic chamber within a custom-built insulated environmental chamber. Each plastic chamber was airtight, with two short copper tubes affixed for air inlet and outlet. A wooden grate was placed in the bottom of the chamber for the bird to stand on. Air temperature within the environmental chamber (here considered ambient temperature, $T_{\mathrm{a}}$ ) was measured using two calibrated Thermochron iButton data loggers (model DS1923, Dallas, TX).

Air was drawn from an unoccupied room (with an open window; high rainfall and humidity and low ambient temperatures meant that we did not use outside air directly) using an air pump (Microvood) and passed through Bev-A-Line tubing (Thermoplastic Processes, Georgetown, DE; ca. $9.5 \mathrm{~mm}$ internal diameter) to a silica gel/soda lime/silica gel column, which scrubbed carbon dioxide and water vapor. The air stream was then split into two lines, the flow rate of each regulated by a mass flow controller (model 840, Sierra Instruments, and MFC2, Sable Systems, Las Vegas, NV), factory calibrated, and then checked against a set of custom-built rotameters. One line supplied the respirometry chamber at $8,000 \mathrm{~mL} \mathrm{~min}^{-1}$, ensuring adequate mixing in the chamber and maintaining $\left[\mathrm{O}_{2}\right]$ depletion of $<0.5 \%$ between the incurrent air and the excurrent air. The excurrent air from the chamber was subsampled with a subsampler mass flow meter unit (SS4; Sable Systems), passed through a soda lime/silica gel column, and then to an Oxzilla II oxygen analyzer (Sable Systems) to measure fractional $\left[\mathrm{O}_{2}\right]$ concentration. The second air stream flowed directly to the oxygen analyzer to establish a baseline and account for any temperature-related drift that may have occurred. Output from the oxygen analyzer was digitized using a Universal Interface II (Sable Systems) and recorded on a personal computer using Expedata data acquisition software (Sable Systems), with a sampling interval of $1 \mathrm{~s}$. Baseline $\left[\mathrm{O}_{2}\right]$ was measured for $20 \mathrm{~min}$ before and after each $\dot{\mathrm{V}}_{2}$ measurement.

The lowest 10 -min mean $\dot{\mathrm{V}}_{2}$ over the test period was assumed to represent resting values, following Liknes et al. (2002). Because carbon dioxide and water vapor were scrubbed before and after passing through the respirometry chamber, oxygen consumption was calculated using equation (9.12) of Lighton (2008). All measurements were obtained at night, during the rest phase of the birds' circadian cycle (Burger 1982). Measurements began at least $30 \mathrm{~min}$ after sunset and ended no later than $30 \mathrm{~min}$ before sunrise. Individual measurement periods lasted 3-6 h. To ensure that birds were awake and resting calmly during measurements, they were monitored inside the chamber with an infrared webcam (Genius eface 1325r). Water was provided ad lib., but food was withheld until after metabolic measurements, which occurred $\geq 9 \mathrm{~h}$ after capture. The allometrically expected passage rate for an average-sized sheathbill (459 g) is $109.7 \mathrm{~min}$, following Ka-

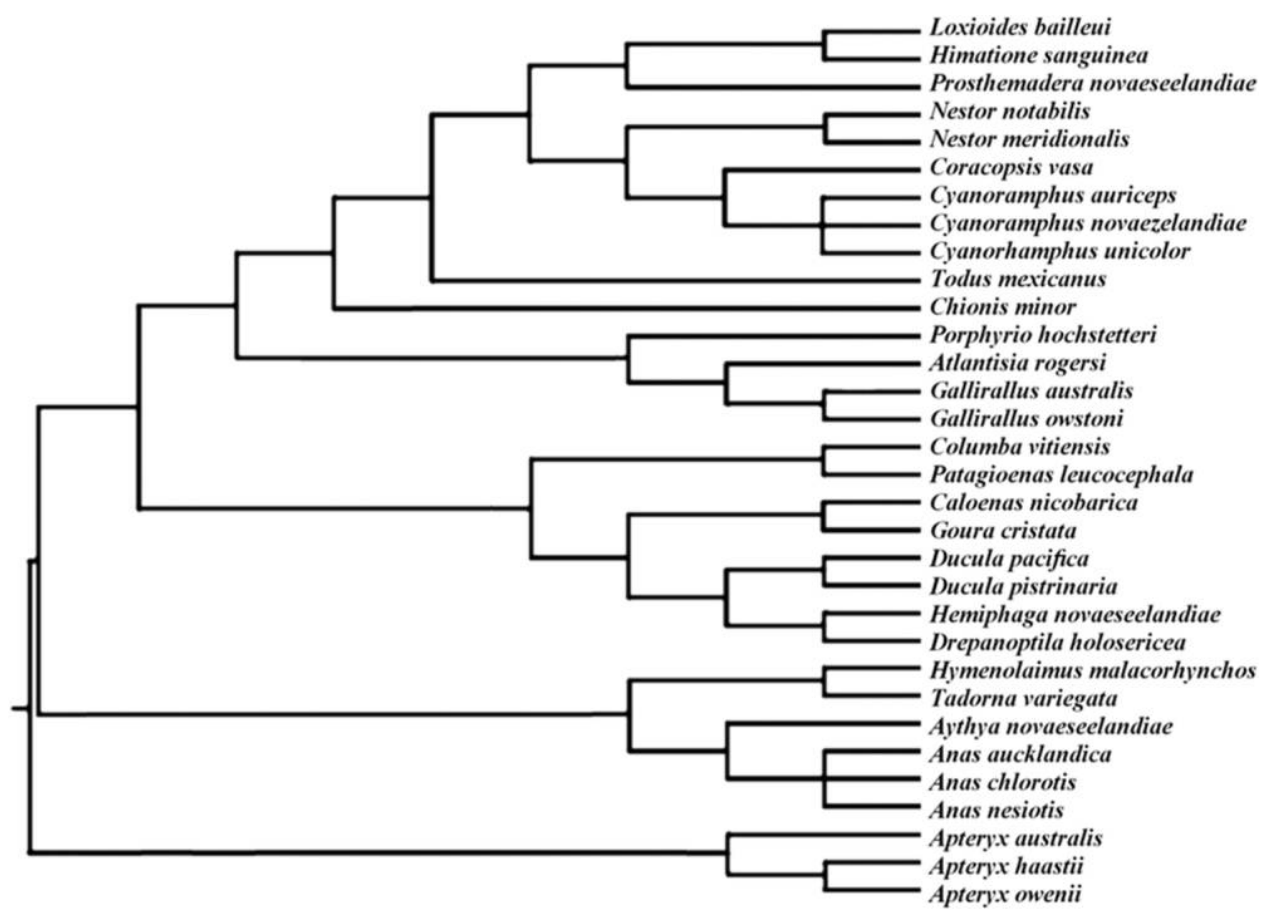

Figure 2. Phylogeny of 32 avian species occurring on islands in which basal metabolic rate has been investigated. 
rasov (1990), and birds could reasonably be considered to be postabsorptive. The oxygen analyzer was tested for temperatureassociated drift (i.e., baseline $\left[\mathrm{O}_{2}\right]$ was measured) every $30 \mathrm{~min}$.

Seven individuals examined were subjected to a ramped $T_{\mathrm{a}}$ profile during each test to determine the thermoneutral zone (TNZ). Each bird experienced temperatures of $1^{\circ}, 5^{\circ}$, and $15^{\circ} \mathrm{C}$ for $3 \mathrm{~h}$, respectively, during a single measurement session. Sheathbills alter their behavior when experiencing exceptionally high temperatures (G. T. W. McClelland, personal field observations), and we sought not to measure stress-related metabolism. We therefore chose $15^{\circ} \mathrm{C}$ as the maximum temperature, given that it is well within the maximum ambient and microclimate temperatures recorded for the island (Chown and Froneman 2008).

Oxygen consumption rate was corrected to milliliters of oxygen per hour at standard temperature and pressure, dry. Sheathbills were assumed to have a respiratory quotient (RQ) of 0.8 during BMR measurements, which minimizes error in the estimated rate of energy expenditure when RQ is unknown (Koteja 1996). Each individual's rate of oxygen consumption was hence converted to metabolic rate (W) using a conversion factor of $20.1 \mathrm{~kJ}$ $\mathrm{L}^{-1} \mathrm{O}_{2}$ (Schmidt-Nielsen 1997). BMR was considered the lowest $\dot{\mathrm{V}}_{2}$ across the range of temperatures measured (Doucette and Geiser 2008) and then subsequently determined for these lowest values for all birds over a consecutive 10 -min period.

\section{Statistical Analyses}

To assess variation associated with temperature, and therefore to determine whether birds were likely to be within their TNZ, we compared metabolic rate among birds measured across the three temperatures using a linear mixed-effects model (Gałecki and Burzykowskie 2013), with bird identity as a random factor and temperature and mass as fixed factors, implemented in the $\mathrm{R}$ package lme 4 (Bates et al. 2011) and fitted using maximum likelihood. Significance was assessed by comparing this model with a null model excluding temperature.

ANCOVA with body mass $\left(M_{\mathrm{b}}\right)$ as a covariate was used to investigate $\mathrm{BMR}$ variation associated with membership of either the KP or RH groups, sex, and molt status after data were checked for normality using Shapiro-Wilks tests. Collinearity among predictor variables was assessed by variance inflation factors (VIFs), adopting a VIF threshold of 5 (Zuur et al. 2010). Least squares means were used in post hoc comparisons. Analyses were performed in the statistical software R 3.0.0 (R Development Core Team 2010).

To compare the BMR of sheathbills to that of other birds, we used the overall mean BMR and body mass of individuals measured from both groups. Sheathbill BMR was compared with that of birds in general using data for wild-caught populations of 137 species analyzed by McKechnie et al. (2006), who used a phylogeny based primarily on Sibley and Alquist (1990). Phylogenetically independent $95 \%$ prediction intervals for the BMR of Chionis minor were calculated using PDTREE, following Garland and Ives (2000). We then repeated this analysis after rearranging the data following the phylogeny proposed more recently by Hackett et al. (2008), to assess the robustness of these conclusions.

The comparison was then narrowed to island endemics using BMR and $M_{\mathrm{b}}$ data for sheathbills in this study and an additional 31 species from the literature (table 1). In view of the general paucity of BMR measurements for island birds, data were included irrespective of sample size or population origin (wild

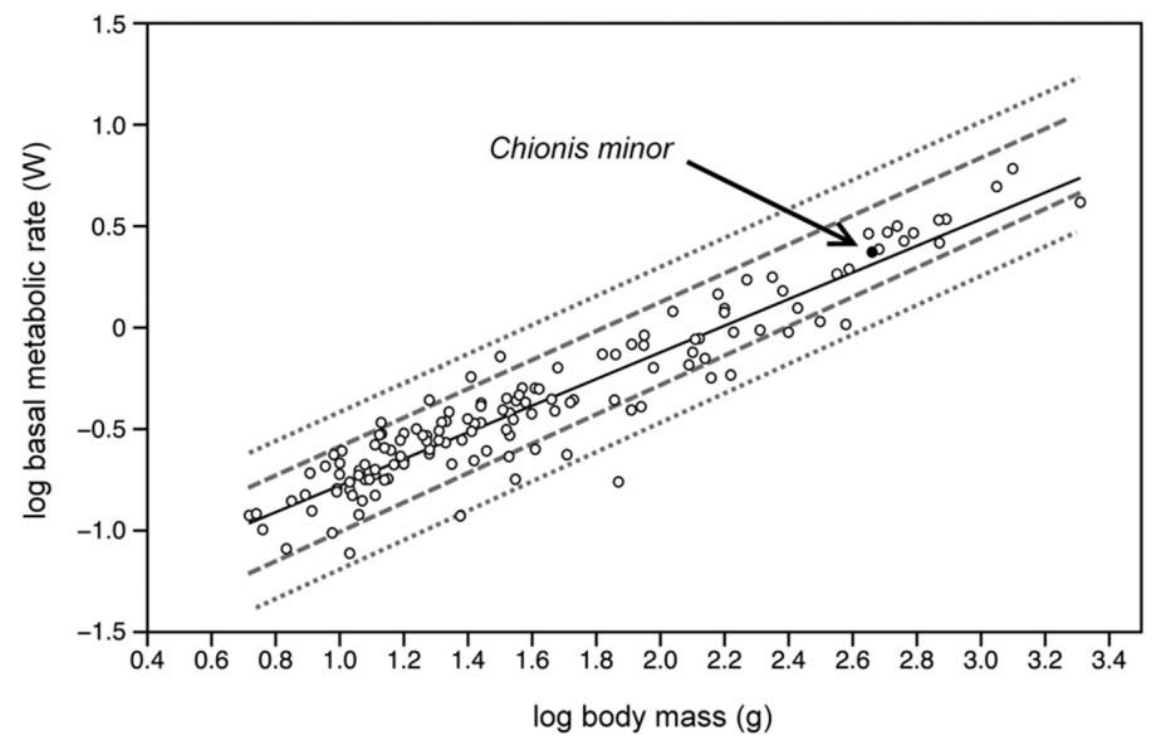

Figure 3. Ordinary least squares (i.e., nonphylogenetically independent) regression of the basal metabolic rate of 137 wild-caught avian species (black line; $\log B M R=-1.437+0.656 \log M_{\mathrm{b}}$ ). The gray dashed and dotted lines represent the phylogenetically independent $95 \%$ confidence and prediction intervals, respectively, based on the phylogeny proposed by Sibley and Alquist (1990). The body mass and basal metabolic rate values for the black-faced sheathbill are highlighted in black. 


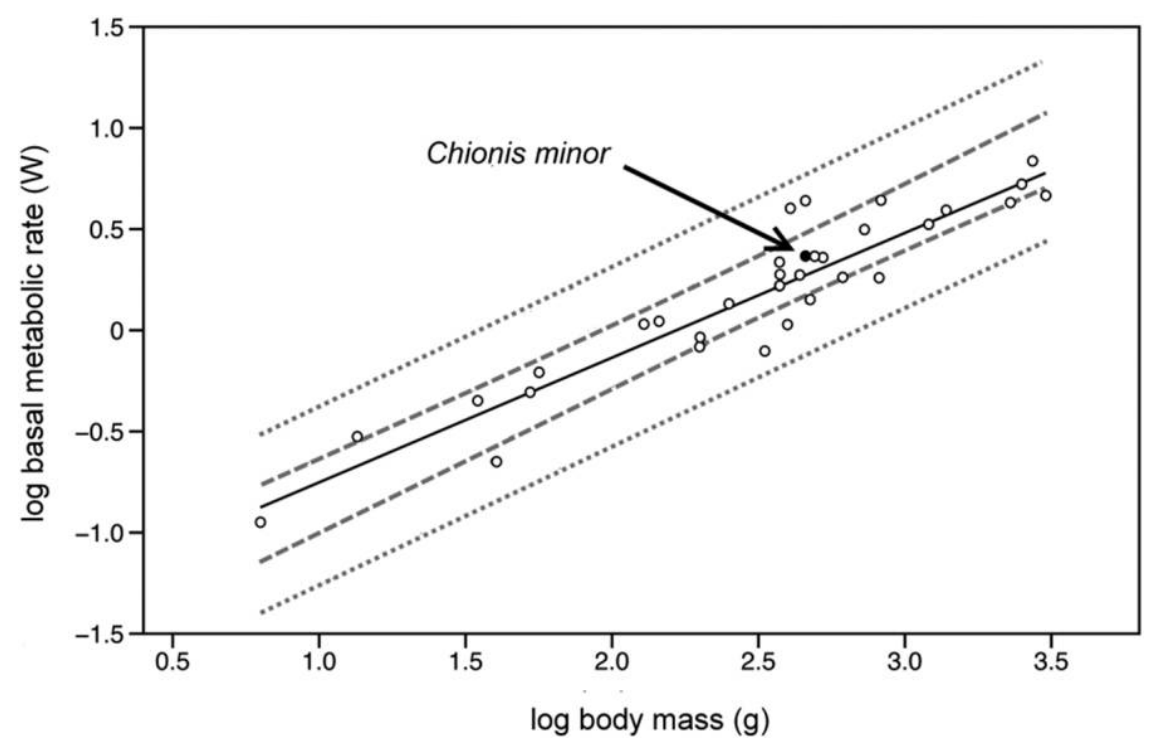

Figure 4. Ordinary least squares regression of the basal metabolic rate of 32 avian species restricted to islands (black line; $\log B M R=-1.369+$ $0.617 \log M_{\mathrm{b}}$ ). The gray dashed and dotted lines represent the phylogenetically independent $95 \%$ confidence and prediction intervals, respectively, based on the phylogeny proposed by Hackett et al. (2008). The black-faced sheathbill is highlighted in black.

caught or captive raised) despite possible influences on results (McKechnie and Wolf 2004; McKechnie et al. 2006). We did not include birds restricted to the island of New Guinea, considering its recent $(<17,000 \mathrm{yr}$ ) separation from Australia (Voris 2000). A phylogeny was constructed based on the topology proposed by Hackett et al. (2008), with relationships within the Psittaciformes, Columbiformes, Gruiformes, Anseriformes, and Apterygiformes based on Wright et al. (2008), Gibb and Penny (2010), Livezey (1998), Donne-Gousse et al. (2002), and Baker et al. (1995), respectively (fig. 2). Because all of the branch lengths in the phylogeny were not known, all branches in the model were set as equal. The phylogenetic variance-covariance matrix required for these analyses was obtained using the PDAP suite (Garland and Ives 2000) within the program Mesquite (Maddison and Maddison 2011) from the respective phylogenies. Phylogenetic signal was assessed following Revell (2010) using the $\mathrm{R}$ package phytools (Revell 2012). Since significant phylogenetic signal was detected (Pagel's $\lambda=0.899 ; 95 \%$ confidence interval $=0.399$, significantly $>0 ; P<0.001$ ), phylogenetically independent prediction intervals based on the sheathbill's position within the phylogeny were again calculated following Garland and Ives (2000).

\section{Results}

The lowest metabolic rates in the ramped $T_{\text {a }}$ profile were recorded at $15^{\circ} \mathrm{C}$, but values were not significantly different across the three temperatures (shown by no difference between the null model and the model including temperature; $\chi^{2}=2.5$, $\mathrm{df}=2, P=0.29$ ), indicating that $15^{\circ} \mathrm{C}$ is not outside the TNZ. For this reason, and because $15^{\circ} \mathrm{C}$ falls within the range of TNZs observed in other Charadriiformes (Gabrielsen et al.
1988, 1991; Bryant and Furness 1995), we undertook further measurements at $15^{\circ} \mathrm{C}$.

Mean mass of the 22 sheathbills was $459.0 \mathrm{~g}(\mathrm{SD}=64$, $\mathrm{min}=$ 360 , $\max =600$ ), and mean whole-animal BMR was $2.370 \mathrm{~W}$ $(\mathrm{SD}=0.464, \min =1.599, \max =3.165)$. The slopes of the regressions were $\log B M R=-1.435+0.657 \log M_{\mathrm{b}}(\mathrm{GLM}: F=$ 1063.4, df $=1,135, P>0.001, r^{2}=0.887$ ) for all wild-caught populations and $-1.366 \log B M R+0.619 \log M_{\mathrm{b}}(\mathrm{GLM}: F=$ $\left.254.9, \mathrm{df}=1,30, P>0.001, r^{2}=0.895\right)$ for island birds. The BMR datum for sheathbills fell within the phylogenetically independent $95 \%$ confidence and $95 \%$ prediction intervals when compared to both other wild-caught populations (figs. 3, A1) and birds restricted to islands (fig. 4). The former conclusion held for analyses based on the phylogenies of Sibley and Alquist (1990) and Hackett et al. (2008).

Body mass and BMR differed significantly between the two sheathbill populations (table 2). Mean KP sheathbill body mass was $20.4 \%$ greater than that of RH sheathbills (Student's $t$-test: $t=4.22$, df $=20, P<0.001)$. Controlling for body mass, BMR differed significantly by habitat type but not by sex or molt score (table 3). Least squares means revealed that mass-corrected BMR

Table 2: Differences in mean body mass and whole-animal basal metabolic rate (WA BMR) in black-faced sheathbills breeding in rockhopper $(\mathrm{RH})$ and king penguin $(\mathrm{KP})$ colonies on Marion Island

\begin{tabular}{lccc}
\hline Population & $\begin{array}{c}\text { Body mass } \\
(\mathrm{g} ; \pm \mathrm{SD})\end{array}$ & $\begin{array}{c}\text { WA BMR } \\
(\mathrm{W} ; \pm \mathrm{SD})\end{array}$ & $n$ \\
\hline RH sheathbills & $421.3 \pm 44.2$ & $2.047 \pm .303$ & 12 \\
KP sheathbills & $507.5 \pm 51.7$ & $2.758 \pm .291$ & 10 \\
\hline
\end{tabular}


Table 3: Results of ANCOVA, using body mass as covariate, analyzing basal metabolic rate in relation to foraging habitat, sex, and molt score in 22 adult black-faced sheathbills on Marion Island

\begin{tabular}{lcccc}
\hline & SS & $F$ & df & $P$ \\
\hline Intercept & .026 & .297 & 1 & .593 \\
Body mass & .139 & 1.584 & 1 & .225 \\
Foraging habitat & .664 & 7.572 & 1 & .014 \\
Sex & .005 & .053 & 1 & .821 \\
Molt score & .001 & .016 & 1 & .902 \\
Error & 1.490 & $\ldots$ & 17 & \\
\hline
\end{tabular}

Note. Foraging habitat refers to either eastern rockhopper penguin colony/ intertidal zone or king penguin colony. Type III sums of squares (SS) are reported. Significant relationships are shown in bold.

in KP sheathbills was $23.9 \%$ higher than that of RH sheathbills $(F=9.144, \mathrm{df}=1,19, P=0.007)$.

\section{Discussion}

Black-faced sheathbills are both phylogenetically and ecologically distinct from many other avian taxa, given their position within the Charadriiformes and status as one of the globe's few temperate island endemics (del Hoyo et al. 2013). In consequence, it was predicted that metabolic rates in this species might be unusual by comparison with other birds. By contrast, the present data suggest that the BMR of sheathbills is typical for a bird of its size. Sheathbill BMR fell within the 95\% prediction intervals of the regression for BMR of both wild-caught birds and island-restricted species. Though the prediction intervals in both analyses were relatively wide, partially a reflection of the distant relationship between sheathbills and other species in the respective phylogenies (Garland and Ives 2000), the relatively close proximity of the black-faced sheathbill to the regression line suggests that narrower intervals would do little to alter this conclusion. Alternative phylogenetic topologies are also unlikely to modify this result, considering that the differing topologies suggested by Sibley and Alquist (1990) and Hackett et al. (2008) both failed to find sheathbills exceptional.

Mass-corrected BMR (i.e., when body mass is included as a covariate in the ANCOVA) was found to vary by up to $24 \%$ between the KP and RH groups. The most plausible potential driver of this variation is differences in resource availability associated with use of these two different kinds of habitats. The RH sheathbills feed both in rockhopper penguin colonies and in the intertidal zone, foraging for polychaetes (McClelland 2013). Polychaete worms have lower energetic values ( $\mathrm{kJ} \mathrm{g}^{-1}$ wet mass) than most benthic invertebrates (Griffiths 1977) and provide considerably less energy than the food items consumed most frequently in penguin colonies (table 4). Sheathbills do not actively seek out individual polychaete worms but must ingest them along with algae (Porphyra sp.; Burger 1981a), which is indigestible to sheathbills (G. T. W. McClelland and S. L. Chown, unpublished data). This need to consume large amounts of poor-quality material alongside polychaetes would presumably make it difficult to compensate for their low energetic value by increasing foraging rate. In addition, the accessibility of the intertidal zone is contingent on tides and sea surface conditions, which interfere with foraging 25.6\% of days (McClelland 2013). During the winter months, $\mathrm{RH}$ sheathbills therefore likely forage on a diet that is of less quality and predictability than KP sheathbills. Thus, sheathbills occupying a superior habitat had higher mass-corrected metabolic rates in comparison to sheathbills occupying a lowerquality habitat despite all individuals experiencing identical abiotic environmental (temperature, rainfall, humidity, solar radiation, and wind) conditions.

Many birds exhibit substantial seasonal variation in BMR (McKechnie 2008; McKechnie and Swanson 2010; Nzama et al. 2010), and it is worth noting that our data reflect a time of year when the two sheathbill groups experience a large difference in food quality and availability. Future studies are necessary to elucidate whether the observed disparity in BMR is present throughout the year or whether metabolic rates in KP and RH sheathbills converge for the 5-mo rockhopper penguin breeding season when food quality, availability, and territorial behaviors for both groups of sheathbills are likely to be similar (Burger 1981a).

BMR is often thought to be associated with habitat quality, and several hypotheses have been proposed to account for the phenomenon, including the food habits hypothesis (McNab 1986), which posits that species or populations that exploit a diet of high quality, availability, and/or predictability are likely to exhibit high mass-corrected BMRs, while lower BMRs are more likely to occur when the diet is of low quality, availability, and/or predictability. The two sympatric yet distinct groups of blackfaced sheathbills on Marion Island represent a natural commongarden experiment, at least as far as climatic factors are concerned, for examining the factors underlying such variation. At this point, it is not clear whether the differences are a consequence of phenotypic plasticity or adaptation. Further work would require both genetic data and common-garden experiments (e.g., such as those of Wikelski et al. 2003) to elucidate the underlying basis of the BMR variation.

Sheathbills are the only terrestrial-endemic birds present on Marion Island and the only terrestrial bird species present on all four Southern Ocean archipelagos. The intraspecific vari-

Table 4: Energy value of the main food items consumed by black-faced sheathbills foraging in king penguin colonies and the intertidal zone on Marion Island

\begin{tabular}{|c|c|}
\hline Habitat and food item & $\mathrm{kJ} \mathrm{g}^{-1}$ wet mass \\
\hline \multicolumn{2}{|l|}{ King penguin colonies: } \\
\hline Kleptoparasitism $^{\mathrm{a}}$ & $4.5-6.8$ \\
\hline Penguin carcasses ${ }^{\mathrm{a}}$ & $4.9-11.6$ \\
\hline Penguin excreta ${ }^{a}$ & 2.1 \\
\hline \multicolumn{2}{|l|}{ Intertidal zone: } \\
\hline Polychaete worms ${ }^{\mathrm{b}}$ & $2.68-4.58$ \\
\hline
\end{tabular}


ation in BMR recorded in this study may play an important role in the species' ability to persist where others have not. Island birds often undergo a niche expansion, demonstrated by an increased range of morphologies and foraging behaviors when compared to their mainland progenitors (Van Valen 1965; Blondel 2000; Whittaker and Fernández-Palacios 2007). There is no reason to assume that this broadening of traits does not extend to physiology. Unfortunately, at present, too few studies have examined intraspecific variation within island species to assess whether this is the case. For example, a search of the literature found only one other endemic bird species (Puerto Rican tody Todus mexicanus Lesson; Merola-Zwartjes and Ligon 2000) that has been studied to a degree that would allow meaningful intraspecific analysis (wild caught, $n>10$ ). The var- iation among the KP and RP sheathbills suggests that greater focus on the energetics of endemic birds may reveal substantial variation associated with island living.

\section{Acknowledgments}

Thanks to Elrike Marais for her initial assistance with the respirometry system. Three anonymous reviewers provided helpful comments on a previous version of the manuscript. This study was funded by South African National Research Foundation grant SNA2011110700005 to S.L.C. and by a South African National Antarctic Programme (SANAP) bursary to G.T.W.M. Logistic support in the field was provided by SANAP.

\section{APPENDIX}

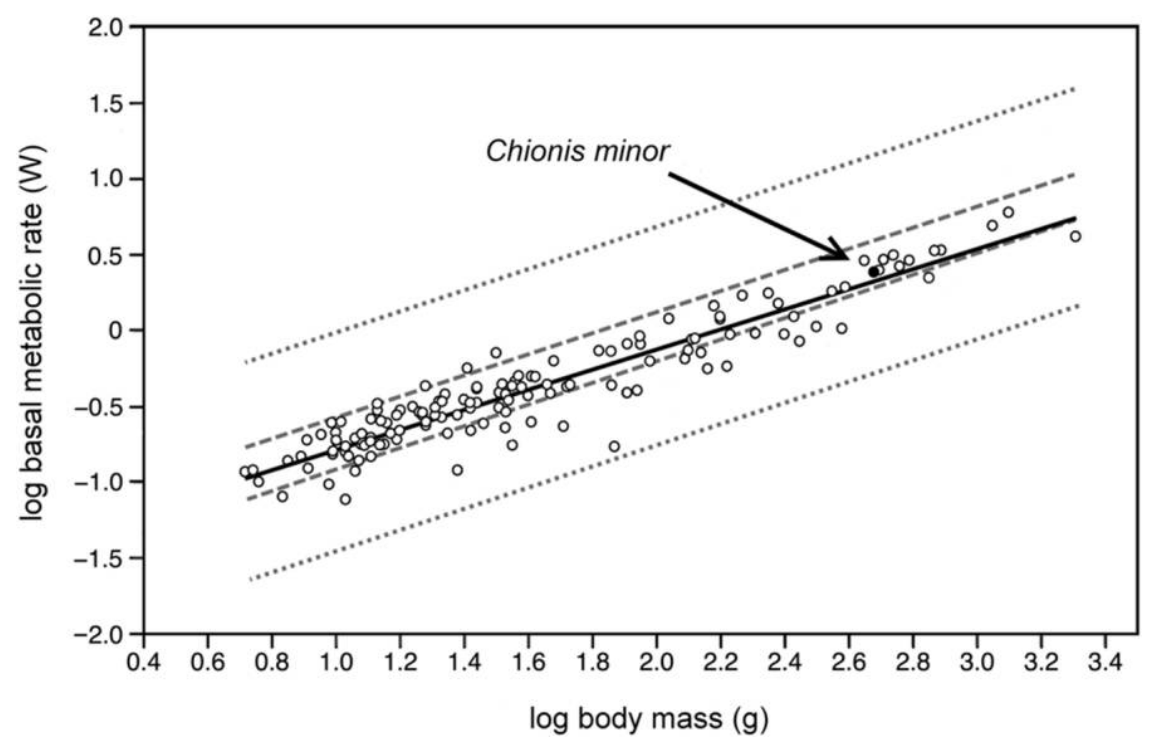

Figure A1. Ordinary least squares (i.e., nonphylogenetically independent) regression of the basal metabolic rate of 137 wild-caught avian species (black line; $\log B M R=-1.437+0.656 \log M_{\mathrm{b}}$ ). The gray dashed and dotted lines represent the phylogenetically independent $95 \%$ confidence and prediction intervals, respectively, based on the phylogeny proposed by Hackett et al. (2008). The body mass and basal metabolic rate values for the black-faced sheathbill are highlighted in black.

\section{Literature Cited}

Baker A.J., C.H. Daugherty, R. Colbourne, and J.L. McLennan. 1995. Flightless brown kiwis of New Zealand possess extremely subdivided population structure and cryptic species like small mammals. Proc Natl Acad Sci USA 92:82548258.

Bates D., M. Maechler, and B. Bolker. 2011. lme4: linear mixedeffects models using S4 classes. R package, version $0.999375-$ 42. R Foundation for Statistical Computing, Vienna. http:// www.r-project.org.

Blondel J. 2000. Evolution and ecology of birds on islands: trends and prospects. Vie Milieu 50:205-220.
Bolnick D.I., P. Amarasekare, M.S. Araújo, R. Bürger, J.M. Levine, M. Novak, V.H.W. Rudolf, et al. 2011. Why intraspecific trait variation matters in community ecology. Trends Ecol Evol 26:183-192.

Bozinovic F., G. Ruiz, and M. Rosenmann. 2004. Energetics and torpor of a South American "living fossil," the microbiotheriid Dromiciops gliroides. LComp Phvsiol B 174:293-297.

Bried J. and P. Jouventin. 1997. Morphological and vocal variation among subspecies of the black-faced sheathbill. Condor 99: 818-825.

Brown J.H., J.F. Gillooly, A.P. Allen, V.M. Savage, and G.B. West. 2004. Toward a metabolic theory of ecology. Ecology 85:17711789. 
Bryant D.M. 1997. Energy expenditure in wild birds. Proc Nutr Soc 56:1025-1039.

Bryant D.M. and R.W. Furness. 1995. Basal metabolic rates of North Atlantic seabirds. Ibis 137:219-226.

Burger A.E. 1980. Sexual size dimorphism and aging characteristics in the lesser sheathbill at Marion Island. Ostrich 51: $39-43$.

- 1981a. Food and foraging behaviour of lesser sheathbills at Marion Island. Ardea 69:167-180.

- $1981 b$. Time budgets, energy needs, and kleptoparasitism in breeding lesser sheathbills (Chionis minor). Condor 83:106-112.

1982. Foraging behaviour of lesser sheathbills Chionis minor exploiting invertebrates on a subantarctic island. Oecologia 52:236-245.

- 1984. Winter territoriality in lesser sheathbills on breeding grounds at Marion Island. Wilson J Ornithol 96:2033.

Chown S.L. and P.W. Froneman. 2008. The Prince Edward Islands: land-sea interactions in a changing ecosystem. Sun, Stellenbosch.

Crawford R.J.M., J. Cooper, B.M. Dyer, M.D. Greyling, N.T.W . Klages, D.C. Nel, J.L. Nel, et al. 2003. Decreases in the number of eastern rockhopper penguin Eudyptes chrysocome filholi at Marion Island, 1994/95-2002/03. Afr I Mar Sci 25: 487-498.

De Beer S.J., G.M. Lockwood, J.H.F.A. Raijmakers, J.M.H. Raijmakers, W.A. Scott, H.D. Oschadleus, and L.G. Underhill. 2001. SAFRING bird ringing manual. ADU guide 5. Avian Demography Unit, University of Cape Town, Cape Town.

Del Hoyo J., A. Elliott, J. Sargatal, D.A. Christie, and E. de Juana, eds. 2013. Handbook of the birds of the world. Lynx, Barcelona.

Donne-Gousse C., V. Laudet, and C. Hanni. 2002. A molecular phylogeny of Anseriformes based on mitochondrial DNA analysis. Mol Phylogenet Evol 23:339-356.

Doucette L.I. and F. Geiser. 2008. Seasonal variation in thermal energetics of the Australian owlet-nightjar (Aegotheles cristatus). Comp Biochem Physiol A 151:615-20.

Gabrielsen G.W., F. Mehlum, and H.E. Karlsen. 1988. Thermoregulation in four species of arctic seabirds. L Comp Phvsiol B 157:703-708.

Gabrielsen G.W., J.R.E. Taylor, M. Konarzewski, and F. Mehlum. 1991. Field and laboratory metabolism and thermoregulation in dovekies (Alle alle). Auk 108:71-78.

Gałecki A. and T. Burzykowskie. 2013. Linear mixed-effects models using R: a step-by-step approach. Springer, New York.

Garland T.J., Jr., and A.R. Ives. 2000. Using the past to predict the present: confidence intervals for regression equations in phylogenetic comparative methods. Am Nat 155:346-364.

Gibb G.C. and D. Penny. 2010. Two aspects along the continuum of pigeon evolution: a South-Pacific radiation and the relationship of pigeons within Neoaves. Mol Phylogenet Evol 56:698-706.

Griffiths D. 1977. Caloric variation in Crustacea and other animals. LAnim Ecol 46:593-605.
Hackett S.J., R.T. Kimball, S. Reddy, R.C.K. Bowie, E.L. Braun, M.J. Braun, J.L. Chojnowski, et al. 2008. A phylogenomic study of birds reveals their evolutionary history. Science 320:17631768.

Hayssen V. and R.C. Lacy. 1985. Basal metabolic rate in mammals: taxonomic differences in the allometry of BMR and body mass. Comp Biochem Physiol 8:741-754.

Huyser O., P.G. Ryan, and J. Cooper. 2000. Changes in population size, habitat use and breeding biology of lesser sheathbills (Chionis minor) at Marion Island: impacts of cats, mice and climate change? Biol Conserv 92:299-310.

Jetz W., R.P. Freckleton, and A.E. McKechnie. 2008. Environment, migratory tendency, phylogeny and basal metabolic rate in birds. PLoS ONE 3:e3261.

Karasov W.H. 1990. Digestion in birds: chemical and physiological determinants and ecological implications. Stud Avian Biol 13:391-415.

Konarzewski M. and A. Książek. 2012. Determinants of intraspecific variation in basal metabolic rate. L Comp Physiol B 183:27-41.

Koteja P. 1996. Measuring energy metabolism with open-flow respirometric systems: which design to choose? Funct Ecol 10:675-677.

Kozlowski J. and M. Konarzewski. 2004. Is West, Brown and Enquist's model of allometric scaling mathematically correct and biologically relevant? Funct Ecol 18:283-289.

Lighton J.R.B. 2008. Measuring metabolic rates: a manual for scientists. Oxford University Press, Oxford.

Liknes E.T., S.M. Scott, and D.L. Swanson. 2002. Seasonal acclimatization in the American goldfinch revisited: to what extent do metabolic rates vary seasonally? Condor 104:548-557.

Livezey B.C. 1998. A phylogenetic analysis of the Gruiformes (Aves) based on morphological characters, with an emphasis on the rails (Rallidae). Philos Trans R Soc B 353:20772151.

- 2010. Phylogenetics of modern shorebirds (Charadriiformes) based on phenotypic evidence: analysis and discussion. Zool L Linn Soc 160:567-618.

Lovegrove B.G. 2000. The zoogeography of mammalian basal metabolic rate. Am Nat 156:201-219.

Lovegrove B.G., M.R. Perrin, and M. Brown. 2011. The allometry of parrot BMR: seasonal data for the greater vasa parrot, Coracopsis vasa, from Madagascar. L Comp Physiol B 181: 1075-1087.

Maddison W.P. and D.R. Maddison. 2011. Mesquite: a modular system for evolutionary analysis. Version 2.74. http:// mesquiteproject.org.

McClelland G.T.W. 2013. The ecology of the black-faced sheathbill (Chionis minor) on Marion Island, subantarctic. $\mathrm{PhD}$ thesis. University of Stellenbosch.

McKechnie A.E. 2008. Phenotypic flexibility in basal metabolic rate and the changing view of avian physiological diversity: a review. L Comp Physiol B 178:235-247.

McKechnie A.E., R.P. Freckleton, and W. Jetz. 2006. Phenotypic plasticity in the scaling of avian basal metabolic rate. Proc $\mathrm{R}$ Soc B 273:931-937. 
McKechnie A.E. and D.L. Swanson. 2010. Sources and significance of variation in basal, summit and maximal metabolic rates in birds. Curr Zool 56:741-758.

McKechnie A.E. and B.O. Wolf. 2004. The allometry of avian basal metabolic rate: good predictions need good data. Phvsiol Biochem Zool 77:502-521.

McNab B.K. 1986. The influence of food habits on the energetics of eutherian mammals. Ecol Monogr 56:1-19.

- 1992. A statistical analysis of mammalian rates of metabolism. Funct Ecol 6:672-679.

1995. Energy expenditure and conservation in frugivorous and mixed-diet carnivorans. LMammal 76:206-222.

- 1996. Metabolism and temperature regulation of kiwis (Apterygidae). Auk 113:687-692.

- 1997. On the utility of uniformity in the definition of basal rate of metabolism. Physiol Zool 70:718-720.

- 2000. The influence of body mass, climate, and distribution on the energetics of South Pacific pigeons. Comp Biochem Physiol A 127:309-329.

- 2002. Minimizing energy expenditure facilitates vertebrate persistence on oceanic islands. Ecol Lett 5:693-704.

- 2003a. Ecology shapes bird energetics. Nature 426: $620-621$.

- 2003b. The energetics of New Zealand's ducks. Comp Biochem Physiol A 135:229-247.

. 2009. Ecological factors affect the level and scaling of avian BMR. Comp Biochem Physiol A 152:22-45.

$\mathrm{McNab}$ B.K. and H.I. Ellis. 2006. Flightless rails endemic to islands have lower energy expenditures and clutch sizes than flighted rails on islands and continents. Comp Biochem Physiol A 145:295-311.

McNab B.K. and C.A. Salisbury. 1995. Energetics of New Zealand's temperate parrots. N Z I Zool 22:339-349.

Merola-Zwartjes M. and J.D. Ligon. 2000. Ecological energetics of the Puerto Rican tody: heterothermy, torpor, and intraisland variation. Ecology 81:990-1003.

Nzama S.N., C.T. Downs, and M. Brown. 2010. Seasonal variation in the metabolism-temperature relation of house sparrows (Passer domesticus) in KwaZulu-Natal, South Africa. Therm Biol 35:100-104.

Piersma T., J.A. Gessaman, A. Dekinga, and G.H. Visser. 2004. Gizzard and other lean mass components increase, yet basal metabolic rates decrease, when red knots Calidris canutus are shifted from soft to hard-shelled food. L Avian Biol 2:99-104.

R Development Core Team. 2010. R: a language and environment for statistical computing. R Foundation for Statistical Computing, Vienna. http://www.r-project.org.

Revell L.J. 2010. Phylogenetic signal and linear regression on species data. Methods Ecol Evol 1:319-329.

- 2012. Phytools: an R package for phylogenetic comparative biology (and other things). Methods Ecol Evol 3: 217-223.

Ryan P.G., B.P. Watkins, and W.R. Siegfried. 1989. Morphometrics, metabolic rate and body temperature of the smallest flightless bird: the inaccessible island rail. Condor 91:465-467.
Schleucher E. and P.C. Withers. 2002. Metabolic and thermal physiology of pigeons and doves. Physiol Biochem Zool 75: 439-450.

Schmidt-Nielsen K. 1997. Animal physiology: adaptation and environment. 5th ed. Cambridge University Press, Cambridge.

Sibley C.E. and J.E. Alquist. 1990. Phylogeny and classification of birds. Yale University Press, New Haven, CT.

Steimle F.W. and R.J. Terranova. 1985. Energy equivalents of marine organisms from the continental shelf of the temperate Northwest Atlantic. L Northwest Atl Fish Sci 6:117-124.

Van Valen L.M. 1965. Morphological variation and width of ecological niche. Am Nat 99:377-390.

Violle C., B.J. Enquist, B.J. McGill, L. Jiang, C.H. Albert, C. Hulshof, V. Jung, et al. 2012. The return of the variance: intraspecific variability in community ecology. Trends Ecol Evol 27:244-252.

Viot C.R., P. Jouventin, and J. Bried. 1993. Population genetics of southern seabirds. Mar Ornithol 21:1-25.

Voris H.K. 2000. Maps of Pleistocene sea levels in Southeast Asia: shorelines, river systems and time durations. L Biogeogr 27:1153-1167.

Weathers W.W. and C. Van Riper III. 1982. Temperature regulation in two endangered Hawaiian honeycreepers: the palila (Psittirostra bailleui) and the Laysan finch (Psittirostra cantans). Auk 99:667-674.

Weathers W.W., D.L. Weathers, and C. Van Riper III. 1983. Basal metabolism of the apapane: comparison of freshly caught birds with long-term captives. Auk 100:977-978.

White C.R., T.M. Blackburn, G.R. Martin, and P.J. Butler. $2007 a$. Basal metabolic rate of birds is associated with habitat temperature and precipitation, not primary productivity. Proc $\mathrm{R}$ Soc B 274:287-293.

White C.R., P. Cassey, and T.M. Blackburn. 2007b. Allometric exponents do not support a universal metabolic allometry. Ecology 88:315-323.

White C.R., P.B. Frappell, and S.L. Chown. 2012. An informationtheoretic approach to evaluating the size and temperature dependence of metabolic rate. Proc R Soc B 279:3616-3621. White C.R. and M.R. Kearney. 2012. Determinants of inter-specific variation in basal metabolic rate. LComp Physiol B 183:1-26.

Whittaker R.J. and J.M. Fernández-Palacios. 2007. Island biogeography: ecology, evolution and conservation. Oxford University Press, Oxford.

Wikelski M., L. Spinney, W. Schelsky, A. Scheuerlein, and E. Gwinner. 2003. Slow pace of life in tropical sedentary birds: a common-garden experiment on four stonechat populations from different latitudes. Proc R Soc B 270:2383-2388.

Wright T.F., E.E. Schirtzinger, T. Matsumoto, J.R. Eberhard, R. Graves, J.J. Sanchez, S. Capelli, et al. 2008. A multilocus molecular phylogeny of the parrots (Psittaciformes): support for a Gondwanan origin during the Cretaceous. $\underline{\mathrm{Mol}}$ Biol Evol 25:2141-2156.

Zuur A.F., E.N. Ieno, and C.S. Elphick. 2010. A protocol for data exploration to avoid common statistical problems. Methods Ecol Evol 1:3-14. 